\section{Nervenlähmung, druckbedingte}

Helga Peter

Marburg, Deutschland

\section{Englischer Begriff}

sleep palsy

\section{Definition}

Sie wird aufgrund der Schlafposition erworben, ist typischerweise beim Aufwachen vorhanden und bildet sich spontan innerhalb kurzer Zeit zurück. Bei erhöhter nächtlicher Arousalschwelle auf $>$,Schmerz", häufig infolge von vorausgegangenem Alkoholkonsum, können längerfristige Nervenausfälle resultieren. Wegen des gehäuften Auftretens der Beschwerden an Wochenenden entstand die Bezeichnung „saturday night palsy“. Betroffen sind vor allem Nerven in den Extremitäten, wie N. ulnaris, N. radialis oder N. peroneus, die streckenweise relativ dicht unter der Hautoberfläche verlaufen und deswegen bezüglich ihrer Leitungseigenschaften bei Druck von mehr als 30 Minuten Dauer störanfällig sind. 